\title{
PROGRAMA MÃE-CANGURU E A RELAÇÃO MÃE-BEBÊ: PESQUISA QUALITATIVA NA REDE PÚBLICA DE BETIM ${ }^{1}$
}

\author{
Jacqueline de Oliveira Moreira* \\ Roberta Carvalho Romagnoli \\ Diego Alonso Soares Dias \\ Carla Borges Moreira
}

\begin{abstract}
RESUMO. Esse texto aborda os resultados de uma pesquisa qualitativa financiada pela FAPEMIG/PUC - Minas que tem como objetivo investigar os efeitos do método "canguru" na relação entre mãe e bebê prematuro. A pesquisa de campo teve seus dados coletados através de entrevistas semiestruturadas junto às mães de bebês prematuros egressas do programa Canguru da Maternidade Municipal Aideé Conroy Espejo, de Betim. Utilizamos a análise de conteúdo por categorias temáticas para a análise dos dados. Os resultados apontam a complexidade da maternidade no interior da prematuridade, atravessada pela vivência de trauma, pelo medo de perder o bebê, pela visão da fragilidade da criança. Nesse contexto, o programa mãe-canguru possibilita efetivamente a conexão entre mãe e bebê prematuro, colaborando para a vinculação da díade. Concluímos ainda que a mãe, os familiares e a equipe podem constituir um ambiente facilitador a partir do momento em que assumam uma postura ativa na mediação da relação do prematuro com o mundo.
\end{abstract}

Palavras-chave: Maternidade, método mãe canguru, prematuridade.

\section{KANGAROO MOTHER PROGRAM AND THE RELATIONSHIP MOTHER- BABY: QUALITATIVE RESEARCH IN A PUBLIC MATERNITY OF BETIM CITY}

\begin{abstract}
This text approaches the results of the qualitative research financed by FAPEMIG and PUC-MINAS and aims to investigate the effects of the kangaroo mother method in the relationship between the mother and the newborn baby. The field research had the data collected by semi structural interviews conducted with the mothers of newborn babies egressed from the Kangaroo program of Betim's Public Maternity named Maternidade Municipal Aidée Conroy Espejo. We utilized the content analyses with thematic categories on data assessment. The results showed the complexity of motherhood inside the prematurity, crossed by the trauma experience, by the fear of losing the baby and by the vision of the child's fragility. In this context, the Kangaroo-Mother Program facilitates the relationship between the mother and the premature baby, contributing to the dyadic's bound. We concluded that mother, family members, and staff can provide a facilitating environment as they take on an active attitude in the mediation between the premature relationship and the world.
\end{abstract}

Key words: motherhood, kangaroo mother method, prematurity.

\section{EL PROGRAMA MADRE-CANGURO Y LA RELACIÓN MADRE-BEBÉ : PESQUISA CUALITATIVADE EN LA RED PÚBLICA DE BETIM}

\begin{abstract}
RESUMEN. Este texto enfoca los resultados de la pesquisa cualitativa financiada pela FAPEMIG / PUC - Minas que tiene como objetivo investigar los efectos del 'método Canguro' en la relación entre madre y bebé prematuro. La pesquisa de campo tuvo sus datos colectados a través de entrevistas semi-estructuradas junto a las madres de bebés prematuros egresas del Programa Ganguro de la Maternidad Municipal Aideé Conroy Espejo, de Betim, Minas Gerais, Brasil. Utilizamos el análisis de contenido por categorías temáticas para el estudio de los datos. Los resultados apuntan para la complejidad de la maternidad en el interior de la prematuridad, atravesada por la vivencia de trauma, por el miedo de perder el bebé, por la visión de la fragilidad del niño. En este contexto, el Programa Madre-canguro posibilita efectivamente la conexión entre madre y bebé prematuro, colaborando para la vinculación de la díada. Concluimos, además, que la madre, familiares, el equipo pueden crear un ambiente facilitador a partir del momento en que asumen una postura activa en la mediación de la relación del prematuro con el mundo.

Palabras-clave: maternidad, método madre-canguro, prematuridad.

\footnotetext{
Apoio: Fundação de Amparo à Pesquisa de Minas Gerais - FAPEMIG e Fundo de Incentivo à Pesquisa - FIP da Pontifícia Universidade Católica de Minas Gerais-PUC-MG
}

* Doutora em Psicologia Clinica, Professora do Mestrado da Pontifícia Universidade Católica de Minas Gerais-PUC-MG.

\# Graduando(a) em Psicologia pela PUC-Minas/Betim.
\end{abstract}




\section{A PREMATURIDADE E O PROGRAMA MÃE CANGURU}

O bebê prematuro ou pré-termo nasce com a idade gestacional menor que 37 semanas e a imaturidade extrema aparece naqueles nascidos com menos de 28 semanas de gestação. Nos nascimentos prematuros, segundo a Organização Mundial de Saúde (WHO, 1961), os bebês apresentam uma série de alterações devidas à imaturidade orgânica, tais como baixo peso e necessidade de auxílio respiratório, além de um alto risco de morte neonatal. De acordo com Segre (2002), nascem anualmente, no mundo, 20 milhões de crianças prematuras, sendo que um terço morre antes de completar um (01) ano. Vale lembrar que, como salientam Andreani, Custódio e Crepaldi (2006), o nascimento prematuro apresenta-se como uma situação traumática também para a mãe, pois, além do risco de perda iminente, esta se vê diante de um bebê diferente do bebê idealizado por ela e pelo pai, frágil e muito pequeno. Acreditamos que nesse contexto se torna difícil inclusive identificar no rosto do filho traços que possibilitem a percepção da herança familiar, e, dessa maneira, favoreçam a construção de um vínculo com o bebê.

O Método Canguru, criado em 1978 pelo Dr. Edgar Rey Sanabria e desenvolvido em 1979 pelo Instituto Materno-Infantil de Bogotá, na Colômbia, constitui, na contemporaneidade, uma importante estratégia que busca promover um melhor desenvolvimento do bebê nascido prematuramente. Tal desenvolvimento, por sua vez, está intrinsecamente relacionado ao estabelecimento de um vínculo afetivo satisfatório entre mãe e filho através de um maior contato corporal entre a criança e sua mãe, ou algum responsável. Em sua criação, o método visava a suprir a falta de recursos materiais e financeiros, a qual impedia que os bebês ficassem integralmente nas incubadoras, como pontuam Colameo e Rea (2006). Somente a posteriori é que se constataram benefícios desse método no desenvolvimento dos bebês.

No Método Mãe-Canguru o bebê é mantido ligeiramente vestido, na posição vertical, junto ao peito de um adulto, ou seja, mantido pele a pele com a mãe ou outra pessoa. As mães participantes do Método Canguru têm os seus filhos envoltos em seu corpo, contidos através de faixas de sustentação e aproximação. Assim, essas mães de prematuros oferecem a seus filhos uma possibilidade de vida fora das incubadoras.

No Brasil, o Método Canguru é realizado em três etapas, e são garantidas todas as condições necessárias para que a criança e a mãe possam realizar o método
(Ministério da Saúde, 2002). Na primeira etapa, o bebê é internado na unidade intensiva e a mãe e a família recebem informações sobre as condições de saúde do bebê, os procedimentos hospitalares, a amamentação e os cuidados que devem realizar, a fim de que tenha uma melhor compreensão da prematuridade. Nessa fase, a estimulação dos pais ao contato com seu filho é muito importante. Sempre que possível, eles podem realizar o contato tátil, sendo este já um trabalho para a criação do vínculo entre os familiares e o prematuro. Na segunda etapa, já com o ganho de peso e a estabilização do bebê, o acompanhamento da mãe pode ser contínuo e a posição canguru já é possível, podendo ser utilizada pelo tempo em que for prazerosa para ambos. A decisão pela participação no método deve resultar de um consenso da mãe, família e equipe do hospital. A mãe aprende a identificar as alterações que podem ocorrer com a criança, como pausas respiratórias, mudança de coloração da pele e outras. A terceira etapa se finaliza com a alta hospitalar, e nesse processo a mãe deve estar preparada, assim como os familiares, pois é indispensável o comprometimento com a continuidade do método. $\mathrm{O}$ bebê deve pesar no mínimo $1.500 \mathrm{~g}$ e ter capacidade de sucção exclusiva ao peito. $\mathrm{O}$ acompanhamento aqui é ambulatorial e sua função caracteriza-se pela realização de exames físicos para a verificação do desenvolvimento desta criança, além de orientação e acompanhamento em possíveis consultas e tratamento especializados (Ministério da Saúde, 2002).

Cabe mencionar que o Método Canguru constitui um caminho que visa a fornecer mais recursos de vida para o bebê e maior contato com a mãe, e deve implicar um número maior de pessoas na sua realização. No entanto, o método muitas vezes fica restrito à técnica, porque, na raro, surge para revolver um problema econômico de falta de incubadoras. Alguns hospitais não escolhem o método como uma alternativa de maior investimento na saúde física e psíquica do bebê, mas para suprir essa carência. A técnica aparece como a única saída para a carência de recursos tecnológicos, embora as questões subjetivas sejam primordiais (Colameo \& Rea, 2006).

O programa mãe-canguru situa-se dentro da Política Nacional de Humanização, que se fundamenta em programas e tem como objetivo humanizar as práticas de cuidado no Sistema Único de Saúde - SUS (Ministério da Saúde, 2004). Nesse contexto, o programa pretende não só favorecer a melhora das condições de saúde do bebê, apresentando uma nova forma de cuidado, mas também incentivar a formação do vínculo entre mãe e bebê. Esperamos desvelar 
parcialmente essa trama que é, em si, complexa, a partir dos resultados encontrados em nosso breve estudo, evidenciando a construção do vínculo a partir do referencial psicanalítico e privilegiando as ideias de Freud e Winnicott.

Este trabalho pretende apresentar os resultados da pesquisa realizada de fevereiro de 2007 a agosto de 2008, que teve como objetivo investigar os efeitos do Método Canguru na relação entre mãe e bebê prematuro $^{2}$. Nessa perspectiva, buscamos, por meio de uma linha de pesquisa qualitativa, desvelar os sentidos subjetivos produzidos pela mãe no processo de construção da relação mãe-bebê prematuro no Programa Mãe-Canguru. Buscamos enfocar a instauração do vínculo de uma mãe com seu bebê prematuro, a partir de sua vivência da prematuridade, de sua interação com a criança e da sua relação com o programa. Destarte é possível percebermos que o presente estudo, ao propor tais objetivos, busca também a construção do conhecimento a respeito do método Canguru a partir de um olhar próprio da psicologia, já que estudos com esse referencial são escassos e é inegável que esse método é um importante dispositivo que interfere na relação mãebebê. É preciso pontuar ainda que a pesquisa de campo qualitativa foi realizada na Maternidade Municipal Aideé Conroy Espejo, no município de Betim, região metropolitana de Belo Horizonte,

\section{METODOLOGIA}

Este estudo se insere na linha de pesquisa qualitativa, sobretudo porque o objetivo do trabalho é investigar os efeitos do Método Canguru na relação entre mãe e bebê prematuro, por meio das percepções e dos significados desse procedimento para as mães que participaram desse programa, com as implicações subjetivas que a prematuridade traz consigo. Problematizando essa modalidade de pesquisa, podemos assinalar que:

(...) a definição do qualitativo na pesquisa psicológica não é uma questão instrumental, nem tampouco uma questão definida pelo tipo de dados que devem ser incluídos, mas que se define essencialmente pelos processos implicados na construção do conhecimento, pela forma de se produzir conhecimento. (González Rey, 2002, p. 24).

2 Pesquisa financiada pela Fundação de Amparo à Pesquisa de Minas Gerais (FAPEMIG) e pelo Fundo de Incentivo à Pesquisa da Pontifícia Universidade Católica de Minas Gerais (FIP-PUC/Minas).
Por este raciocínio, a pesquisa qualitativa corresponde a uma opção epistemológica, e não somente à distinção metodológica entre o quantitativo e qualitativo, nem ao uso de procedimentos metodológicos específicos. Cabe ressaltar que a abordagem qualitativa do estudo da subjetividade persegue a elucidação de processos complexos, a busca de sentidos subjetivos e de processos de significação a partir dos quais se dá a construção do conhecimento. Nessa perspectiva, o conhecimento emerge da combinação de processos de produção teórica e empírica, não em uma relação direta e linear, mas de maneira processual e singular. Conforme Chizzotti (1998), essa processualidade é dinâmica, e aposta na relação assídua entre o mundo objetivo e o mundo subjetivo. Vale lembrar que a forma de produção qualitativa de conhecimento se destaca pelo seu caráter interpretativo, singular e em permanente desenvolvimento.

A partir dessa abordagem metodológica, o universo de pesquisa foi composto pelas mães de prematuros cadastradas no Programa Canguru da Maternidade Aideé Conroy Espejo - Maternidade Municipal de Betim, no segundo semestre de 2005. Três são os elementos que definem o perfil das oito (08) mães entrevistadas: primeiro, o filho ter nascido entre trinta (30) e trinta e duas (32) semanas de idade gestacional, sem complicações clínicas e com peso médio de um (01) quilo a dois (02) quilos; segundo, ter participado do Programa Mãe Canguru; e, terceiro, o filho ter na ocasião da entrevista aproximadamente dois (02) anos. Acreditamos que este último fator criaria possibilidades para as mães falarem livremente nas entrevistas, uma vez que o tempo é um agente fundamental para a elaboração da difícil situação do nascimento prematuro. Pelos dados coletados nas entrevistas, acreditamos ter sido um elemento favorável ao estudo.

Tabela 1. Perfil das Mães Entrevistadas Segundo Dados do Nascimento

\begin{tabular}{lccccc}
\hline Filho & $\begin{array}{c}\text { Motivo da prematu- } \\
\text { ridade segundo a mãe }\end{array}$ & Sexo & $\begin{array}{c}\text { Peso no } \\
\text { nascimento }\end{array}$ & $\begin{array}{c}\text { Internação } \\
\text { anterior ao } \\
\text { método canguru Programa }\end{array}$ & $\begin{array}{c}\text { Permanên } \\
\text { cia no }\end{array}$ \\
\hline F1 & Pressão alta & Fem. & $1.960 \mathrm{~g}$ & 12 dias & 16 dias \\
F2 & Eclampse, convulsão & Fem. & $2000 \mathrm{~g}$ & 06 dias & 7 dias \\
F3 & Pressão alta & Mas. & $1.640 \mathrm{~g}$ & 15 dias & 22 dias \\
F4 & Infecção de urina & Fem. & $2000 \mathrm{~g}$ & 15 dias & 12 dias \\
F5 & Pressão alta & Fem. & $1.640 \mathrm{~g}$ & 14 dias & 15 dias \\
F6 & Não informado & Mas. & $1.770 \mathrm{~g}$ & 30 dias & 3 dias \\
F7 & Perda de líquido e & & & & 61 dia \\
F8 & contração & Fem. & $1.780 \mathrm{~g}$ & & \\
\hline
\end{tabular}

É necessário informar ainda que as oito mães entrevistadas eram casadas e apresentavam estabilidade conjugal. Não trabalhamos outros dados de caracterização 
das mães, tais como escolaridade, renda mensal e outros, porque nosso interesse era a experiência subjetiva dessas mães na rede publica de saúde do Programa Mãe Canguru; mas podemos dizer que o público desse programa e o local pesquisado sugerem que as mães pertencem às camadas sociais baixas. Conforme Boudon e Bourricaud (1993), esse estrato social constitui-se como um estrato de baixo poder aquisitivo, possuindo moradia precária, baixa instrução e baixo nível de qualificação.

Para que se coletassem os nomes das mulheres que seriam entrevistadas foram necessárias algumas visitas à maternidade. Nessas visitas obtivemos acesso ao livro de registros da maternidade, o qual ficava na sala do Programa Mãe Canguru, continha alguns dados referentes ao bebê e os nomes de diversas mães que atendiam ao critério citado (mães cadastradas no segundo semestre de 2005) e tinham passado pelo programa. Além dos nomes, foi possível, com a ajuda de algumas funcionárias, conseguir o endereço e telefone das mães com a ajuda, o que tornava possível o início do trabalho de campo. Em um universo de vinte e nove (29) mães que participaram do Programa Mãe Canguru em 2005, foram selecionadas vinte e seis (26) mães, sendo dezesseis (16) mães primigestas e dez (10) mães multigestas. Essas mães respondiam ao perfil estabelecido de ser mãe de filho nascido de trinta (30) a trinta e duas (32) semanas e com o peso de um a dois quilos. Não obstante, os telefones de muitas das mães estavam desatualizados e muitas delas não possuíam telefone, o que não permitia o contato com elas. A dificuldade de acesso às mães foi um dos fatores determinantes para restringir as entrevistas a oito mães. $\mathrm{O}$ baixo nível socioeconômica da população atendida pela maternidade, como mencionado acima, trouxe dificuldades de acesso a essas mulheres, pois muitas não têm telefone e, por vezes, nem residência fixa; no entanto é preciso ressaltar que o fator preponderante para a limitação das entrevistadas a oito (08) mães foi a riqueza dos dados coletados com as mães entrevistadas, o que assegurou o material necessário para a interpretação dos dados subjetivos que focalizamos em nosso estudo.

Tabela 2. Perfil das Mães Entrevistadas Segundo Idade e Número de Filhos

\begin{tabular}{lcc}
\hline Nome da mãe & Idade da mãe & Número de filhos \\
\hline M1 & 35 anos & 01 (uma) filha \\
M2 & 24 anos & 01 (uma) filha \\
M3 & 32 anos & 04 filhos ( $4^{\circ}$ prematuro) \\
M4 & 24 anos & 01 (uma) filha \\
M5 & 28 anos & 01 (uma) filha \\
M6 & 34 anos & 03 filhos ( $3^{\circ}$ prematuro) \\
M7 & 29 anos & 02 filhas ( $2^{\circ}$ prematura) \\
M8 & 34 anos & 03 filhos ( $3^{\circ}$ prematuro) \\
\hline
\end{tabular}

Para se aprofundar a investigação em seu aspecto qualitativo, essas entrevistas foram semiestruturadas, com roteiro previamente estabelecido, e realizadas nas casas das mães pelos estagiários da pesquisa. Foram entrevistadas oito (08) mães, como exposto acima, sendo quatro (04) primigestas de filho prematuro e quatro (04) multigestas que não tiveram o primeiro filho prematuro. As entrevistas foram devidamente gravadas e transcritas, atendendo às normas do comitê de ética em pesquisa da PUC-Minas. O instrumental de análise dos dados obtidos nas entrevistas constituiu-se da análise de conteúdo e das categorias temáticas oriundas deste procedimento de interpretação. Devido à combinação de rigor e sistematicidade, à natureza do material coletado e ao objetivo proposto por esta pesquisa, a análise de conteúdo foi escolhida para ser utilizada neste trabalho. Da análise de conteúdo utilizamos mais precisamente sua proposta acerca do sistema de categorias, com o intuito de organizar e sistematizar os pontos que emergiram das entrevistas realizadas. As unidades de registro usadas foram temas, porque, segundo Bardin (1994), a análise temática permite descobrir os sentidos que atravessam a comunicação e a frequência que a compõe indica significados para o objetivo analítico.

A análise temática efetivada foi de cunho qualitativo, o que significa dizer que se deu especial ênfase à presença dos temas elaborados para serem pesquisados, em detrimento da frequência com que estes aparecem ao longo dos relatos. Sendo assim, o material foi codificado por categorias temáticas e os temas foram definidos a posteriori, a partir do que surgiu nas entrevistas realizadas, focando as seguintes categorias temáticas: vivência da prematuridade, interação com a criança e percepção do Programa Canguru.

\section{RESULTADOS E DISCUSSÃO}

Para investigar os efeitos subjetivos do Programa Mãe Canguru no processo de construção da relação mãe-bebê foi necessário pesquisar, primeiro, as relações da mãe com a situação da prematuridade. Dessa forma, a discussão dos resultados apresenta a posição materna em relação à vivência da prematuridade ressaltando a experiência do trauma da ruptura e interrupção da gravidez. Após levantar os elementos que dizem respeito ao parto prematuro, buscamos pesquisar as fantasias e medos das mães em relação ao seu bebê prematuro. As mães vivem o pavor da morte iminente de seus filhos, pois os vêem como frágeis, e, ainda, ficam decepcionadas na 
ocasião do nascimento, pois o filho não corresponde à imagem idealizada de um bebê. Diante dessa situação traumática, as mães, por vezes, não conseguem se vincular a seus filhos ou, no outro extremo, superprotegem os bebês. Considerando-se esse conjunto de elementos, o Programa Mãe Canguru é decisivo na formação de um vínculo possível entre a mãe e seu bebê prematuro. O Programa Mãe Canguru possibilita à mãe a segurança básica necessária à construção da maternagem. Assim, apresentamos as discussões sobre os resultados nessa ordem, enfatizando um modelo discursivo de apresentação de resultados. Buscamos ainda refletir sobre os temas dialogando com as teorias clássicas da psicologia sobre a relação mãe-bebê, como a teoria freudiana e a winicottiana. $\mathrm{Na}$ verdade, observamos em nosso levantamento bibliográfico para a efetuação desse estudo que as pesquisa no campo em psicologia sobre o Programa Mãe Canguru são escassas, o que limita o campo de diálogo nesta área. Não obstante, esperamos que nossa pesquisa venha a contribuir para um ciclo de reflexões tipicamente psicológicas sobre o tema.

A primeira categoria de análise, "Vivência da prematuridade", buscava compreender de que forma as mães lidavam com a situação em que se encontravam, a saber, o nascimento prematuro de seu filho. Sem dúvida, o nascimento prematuro apresentase como uma situação traumática para o bebê e para a mãe. Como vimos acima, o bebê prematuro sofre alto risco de morte neonatal, tem baixo peso e necessidade de auxílio respiratório. Por outro lado, a mãe precisa elaborar o nascimento repentino, sendo que, na maioria das vezes, não pode abrigar no colo seu filho, que nasce tão diferente do que foi imaginado. De que o nascimento prematuro é traumático não há duvida; mas quais são os índices que possibilitam ao pesquisador afirmar que as mães vivenciam uma experiência traumática? Buscamos na teoria freudiana a possibilidade de construir um índice que determina o caráter traumático de uma experiência. Esse elemento é a vivência do tempo. Freud revela que uma situação traumática rompe as barreiras protetoras do sistema perceptivo pela invasão de um excesso de estímulos, produzindo uma suspensão temporal. $\mathrm{O}$ trauma produz uma falha na temporalização, porque a origem da noção de tempo se vincula à construção de uma barreira protetora para o psiquismo que o protege dos estímulos externos. Mas, essa barreira deve produzir um movimento rítmico de abertura e fechamento e assim cria-se o ritmo do tempo. Freud revela:

(...) nossa ideia abstrata de tempo parece ser integralmente derivada do método de funcionamento do sistema Pcpt - Cs. e corresponder a uma percepção de sua própria parte nesse método de funcionamento, o qual pode talvez constituir uma outra maneira de fornecer um escudo contra os estímulos (Freud, 1920/1989, p. 44).

A forma do tempo é essencial para a construção da experiência. As excitações externas devem atingir o sistema perceptivo/consciência mediante rápidos impulsos periódicos. A não-excitabilidade periódica ou descontinuidade na corrente de inervações protege o organismo da morte pelo excesso e permite a distinção qualitativa dos estímulos. Freud refere que “(...) o método descontínuo de funcionamento do sistema Pcpt - Cs jaz no fundo da origem do conceito de tempo" (Freud, 1924/1989, p. 290).

O tempo tem sua origem na descontinuidade, pois é essa ideia que permite a criação do processo de periodização e, assim, possibilita a apreensão da experiência pela diferenciação qualitativa dos estímulos. Uma situação traumática derruba as barreiras protetoras do psiquismo e uma grande quantidade de energia inunda esse aparelho. Fica claro, assim, que este excesso energético produzido pelo trauma coloca o sujeito fora do tempo. Freud afirma que "(...) o conceito de trauma implica necessariamente uma conexão desse tipo com uma ruptura numa barreira sob outros aspectos eficazes contra os estímulos" (Freud, 1920/1989, p. 48). Essa confusão temporal é apresentada por todas as entrevistadas. As mães entrevistadas não conseguem localizar o momento da internação, o tempo do parto e outros elementos temporais implicados no nascimento.

Assim, esse trauma apresenta uma vivência de ruptura/interrupção de uma expectativa de normalidade que se expande através dos dias, pois é negada a essa mães a possibilidade de voltar para casa com seus filhos, e nesse momento as mães são privadas de seu objeto de amor. A teoria freudiana ,em sua reflexão sobre a condição humana de ser castrado, assinala que os sujeitos, ao longo da vida, buscam investir em objetos que possam imaginariamente tamponar essa falta constitutiva do humano. No caso especifico das meninas, Freud afirma que, na resolução do Édipo, ou seja, no reconhecimento da falta como estruturante da subjetividade, a menina aposta na possibilidade de um filho como um falo substituto. Nas palavras de Freud, “(...) a renúncia ao pênis não é tolerada pela menina sem alguma tentativa de compensação. Ela desliza - ao longo da linha de uma equação simbólica, poder-se-ia dizer — do pênis para um bebê" (Freud, 1924/1989, p. 223). Assim, a possibilidade de elaborar o luto de perder a condição poderosa de grávida só é remediada pela possibilidade 
de ter o bebê no colo. A "síndrome do colo vazio" fere o centro do narcisismo feminino e essa ferida se agrava com a possibilidade real de o filho não sobreviver.

Todas as mães sofrem com o "risco iminente de morte da criança", seja por questões de cunho objetivo (os riscos efetivos que a criança apresenta), seja por questões de ordem subjetiva (a concepção também imaginária das mães da fragilidade em que se encontra seu bebê). É válido acrescentar que essas questões de ordem subjetiva encontram-se intrinsecamente ligadas ao surgimento da preocupação materna primária, que se inicia nos últimos meses de gravidez, e, segundo Dias (2003), é o estado que advém com a maternidade. Esta se encontra relacionada à identificação da mãe com seu bebê e à capacidade da mãe de suprir as necessidades básicas da criança em um primeiro momento. Dessa forma aquele bebê, que se encontra muito distante da criança sonhada, é percebido como frágil e pequeno, portanto incapaz de se desenvolver por movimentos próprios. A fantasia de morte aparece por meio do significante quieto, sem movimentos. As mães, quando observam seus filhos nas incubadoras, pensam que estes se encontram imóveis. Segundo Dias, “(...) a vida, para o bebê, é movimento, (...) desde o início, é preciso ter o cuidado de "evitar qualquer entrave à expressão de seu movimento". (Dias, 2003, p. 183). Parece-nos que esta imagem da imobilidade se vincula à ideia de uma criança sem ritmo e sem movimento, sem disponibilidade para a díade.

Nesse contexto, percebemos que havia uma superação física da mãe, que demonstrava a força existente nas mães para se encontrar com seus filhos, buscando a certeza de que eles estivessem bem. O que ocorria era o seguinte: as mães, diante da ansiedade de estarem com seus filhos, superavam o momento difícil em que se encontravam logo após o parto, inclusive fisicamente debilitadas, para se encontrarem com seus filhos; ou seja, as mães visavam superar, desse modo, a privação de seu objeto de amor a elas imposta. Nessa luta entre um narcisismo de vida e um narcisismo de morte, o narcisismo de morte demanda do sujeito fechar-se em si mesmo e ser prisioneiro da dor, mas, por outro lado, o narcisismo de vida clama pela aposta na vida, levando as mães a investir em seus filhos. As mães de crianças prematuras muitas vezes escolhem o narcisismo de vida e se levantam para acolher a nova vida. Afinal, a criança necessita ser cuidada e, conforme mencionamos, a mãe já está envolvida em um processo de identificação com seu bebê, iniciado nos últimos meses de gravidez. A mãe encontra-se disponível e pronta para suprir todas as necessidades de seu filho e para ela é então fundamental saber do seu estado.

Não obstante, esses acontecimentos, em um momento posterior, podem levar ao surgimento de peculiaridades no desenvolvimento infantil, uma vez que a mãe, ao se comportar dessa maneira, toma para si a tarefa de ser infalível, o que entra em conflito com o curso "normal" da vida da criança, pois é necessário que a mãe "falhe" no desenvolvimento infantil, porquanto são justamente essas falhas que permitem à criança relacionar-se com o mundo a seu redor. Assim, aquilo que em um primeiro momento se mostra um narcisismo de vida, revelando uma aposta materna em uma vida que se mostra frágil, pode tomar outros rumos no que se refere à criança, pois ela, diante dessa superproteção, encontra-se fechada e impossibilitada de se relacionar com o mundo, visto que se encontra envolvida por uma mãe que não cessa de suprir suas necessidades.

Na segunda categoria de análise, "Interação com a criança", averiguamos de que maneira se dava a construção da relação entre mãe e criança. A primeira questão a ser apontada é choque entre o filho imaginado e o filho real. Todas as mães precisam fazer o luto do filho imaginado, pois, ao nascer, o bebê preenche um espaço que na realidade era preenchido por fantasias; mas no caso da mãe do prematuro a distância entre as fantasias e a realidade é verdadeiramente cruel, pois o bebê comumente pesa gramas, não consegue respirar sem ajuda de equipamentos e é quase um bebê ainda em construção. Não obstante, se por um lado a fragilidade do bebê dificulta o vínculo, por outro é exatamente a fragilidade que convoca essas mães a responder. Nesse ponto é preciso que o Método Canguru intervenha para a construção do vínculo, pois a possibilidade de essa mãe ter de volta em seu corpo o bebê arrancado cria espaço para a reconstrução rítmica dessa díade. Destarte, o método possibilita o resgate de um tempo perdido, de um tempo que foi tomado da mãe e da criança, a partir do nascimento prematuro. Assim, o contato pele a pele permite, no caso das mães, a elaboração de um evento que ocorreu de forma tão brusca e violenta, capacitando-a a lidar até mesmo com a fragilidade existente na criança e dar continuidade ao luto da criança imaginária. As condições para que a preocupação materna primária ocorra são restabelecidas. A teoria winnicottiana nos revela que bebê não é uma unidade em si mesmo, ele caminha para uma integração psíquica a partir da adaptação do seu entorno, sobretudo da mãe, às suas necessidades. Nessa proposta, não há distinção entre mundo interno e externo, mas sim, uma 
indissociabilidade entre bebê e ambiente, ou seja, "O ambiente - que, no início é a mãe, ou melhor, os modos de ser da mãe - é parte do bebê, indistinguível dele" (Dias, 2003, p. 130). Assim, o Método Canguru possibilita essa adaptação do ambiente às necessidades de bebê.

É necessário assinalar que a percepção da fragilidade dos bebês produz nas mães um "efeito de superproteção", como foi apontado na categoria anterior; mas buscamos novos elementos para pensar na superproteção. Buscamos entendê-la a partir da afirmação winnicottiana de que o bebê amadurece por impulsos próprios; não é a mãe que produz o amadurecimento, ela atua apenas como facilitadora do processo. No entanto, no caso do bebê prematuro, que precisa de intervenções mais incisivas do ambiente, a mãe pode sentir que o bebê só sobreviveu e sobrevive por causa das intervenções externas. Nesse contexto, é mais que evidente a mãe concluir que a sua vida depende sobremaneira do outro e, assim, fica estabelecido o caminho imaginário para a superproteção. Vale lembrar que a mãe superprotetora não se enquadra na definição de "mãe suficientemente boa", porque o advérbio da expressão contém em si os limites do cuidado. Dias revela que a bondade suficiente aponta para a “(...) capacidade de acreditar que o bebê é um processo de amadurecimento em curso e que, portanto, não é ela - seus cuidados ou controle da situação - que dará vida ao bebê" (Dias, 2003, p. 133). Parece importante enfatizar que as mães veem a superproteção a partir de uma projeção no filho, assim é a criança que "superdepende" da mãe.

Na categoria "Percepção do Programa Canguru" observamos que todas as mães são unânimes em falar da importância da estratégia, que as ajudou a levar a cabo a tarefa da prematuridade. Na maioria das vezes a equipe consegue promover um ambiente propício ao desenvolvimento da criança, contribuindo paras as mães conseguirem exercer a maternagem. $\mathrm{Na}$ ocasião do nascimento e logo após, as mães se sentem inseguras no ato de cuidar de suas crianças e necessitadas de auxílio nessa atividade. Nesse momento as informações e o apoio fornecidos pela equipe são essenciais. Inclusive, observamos em algumas das entrevistadas que a equipe é percebida como realizadora de sustentação afetiva, e não somente técnica, escutando os medos, as dificuldades, dando amparo para a situação. Percebemos que é frequente o uso da estratégia de valorização do bebê por parte dos profissionais da equipe, o que contribui para que a mãe consiga se vincular a seu filho e invista no bebê.
As mães entrevistadas, que participaram do Programa Mãe Canguru, ressaltaram a influência positiva da participação do pai, que entrava auxiliando a mãe e contribuindo para o desenvolvimento do bebê. Muita das vezes a mãe não tinha condições físicas e/ou subjetivas para realizar os procedimentos previstos, e era o pai que o fazia, ajudando, dessa maneira, tanto a mãe quanto o bebê. Outro ponto positivo foi a possibilidade de compartilhar as experiências com outras mães que estavam na mesma situação. Trocar atitudes, dificuldades e sentimentos as fazia sentir-se menos solitárias nesse processo.

Notamos ainda que algumas mães fazem uso singular do método, não se atendo às instruções fornecidas, mas encontrando saídas singulares para ser mãe de um bebê prematuro. Essa singularidade apareceu na forma de dar as mamadas e de executar o método. Observamos nas falas que a maneira de se apropriar do programa e de se vincular ao bebê é única e de cada mãe, mesmo que para isso tenha que desobedecer às instruções recebidas. Por outro lado, uma das mães somente consegue estabelecer o vínculo com seu bebê quando faz conexão com a religião :ela passa a rezar e isso ameniza a dificuldade de viver a prematuridade e a sensação de ser imprestável como mãe.

As mães, dessa forma, libertavam-se das exigências da equipe e construíam o seu modo de ser mãe, acontecimento extremamente significativo, principalmente nas mães que possuíam mais filhos. Revela-se aqui uma postura ativa no processo de ser mãe, o que pode ter intrínseca relação com a experiência adquirida com as outras crianças. Assim, mesmo diante das inseguranças e medos provenientes da prematuridade, elas conseguiam se apropriar da experiência do método, fazendo-o do seu jeito. Por outro lado, é possível percebermos que fatos semelhantes aconteceram com as mães que não possuíram outros filhos. Ainda que em um primeiro momento ocorresse um desconhecimento da posição ocupada por elas (condição materna), pelo fato de serem “mães de primeira viagem", era possível percebermos que as mães sentiam-se, dentro de algum tempo, aptas a construir a experiência de uma maneira não alienada, libertando-se daquilo que lhes era imposto. Talvez seja possível dizermos que, assim como a mãe supre as necessidades afetivas e psíquicas da criança, envolvendo-a e tornado-se um ambiente seguro para o bebê, a equipe, e até mesmo o pai, tornaram o ambiente seguro para a mãe, suportando-a psíquica e afetivamente, sendo este um aspecto que otimizava o desenvolvimento da criança prematura. 
Não obstante, outros aspectos peculiares se revelaram no que se refere às mães que possuíam mais filhos, já que, para algumas mães, os outros filhos, principalmente aqueles mais novos, eram motivo de preocupações enquanto elas estavam no hospital. Por outro lado, era-lhes necessário devotamento e entrega em prol do filho prematuro, que necessitava cuidados. Conforme observamos anteriormente, a segunda etapa do método diz justamente da execução do programa no maior tempo possível, o que fazia com que as mães passassem muitas horas no hospital. No entanto, era justamente essa entrega que fazia com que as mães ficassem bastante tempo longe do lar, conduta essa que não compete à "mãe ideal". Nesse momento vizinhos e familiares entravam em cena e supriam essa deficiência. No caso de mães que possuíam filhas já adolescentes, foi possível percebermos que elas desempenhavam um papel fundamental, cuidando da casa e de seus irmãos mais novos.

Observamos que certo modelo de ser mãe atravessa o programa Mãe Canguru e se relaciona com a sensação de incapacidade de ser mãe que acompanha a maioria das entrevistadas. Essa sensação, de certa maneira, foi reforçada pela equipe, que, sem se dar conta, parte de uma visão de mãe e de um modelo ideal que devem ser seguidos. Esse traço também foi percebido por Moura e Araújo (2005), ao estudarem os sentidos da maternidade na área de saúde. Fundamentados nas ideias de Foucault (1996) na leitura das relações de poder que se exercem no cotidiano a partir da associação com o saber, podemos afirmar que o Programa Mãe Canguru também constitui um entrelaçamento de relações entre seus participantes. Essas relações são tecidas em torno de como os trabalhadores de saúde exercem suas funções e de como as mães se posicionam a partir disso. Segundo o autor, todo discurso científico se encontra também articulado com fatores sociais, políticos, econômicos, tecnológicos e pedagógicos. Esse discurso de fato é uma prática discursiva que "fabrica" aquilo no qual se propõe a intervir. Dessa maneira, o Programa Canguru recebe uma ordenação estabelecida pelos critérios de cientificidade tanto da psicologia quanto da medicina, fundamentando as suas práticas.

O dia-a-dia do programa se apoia em rituais, horários e procedimentos hospitalares em que as mínimas regras são sustentadas por formações discursivas, entre os quais o "como ser mãe", que é também produto dessas articulações e dos saberes que o atravessam. O modelo ideal de mãe circula no cotidiano das pessoas, introjetado em cada um de nós, moldando subjetividades, docilizando os corpos. Essa relação de submissão e assujeitamento emerge na fala das entrevistadas quando o programa impõe às mães uma única maneira de exercer a maternidade, calcada no modelo idealizado. Nessa imposição, sentidos vão sendo produzidos e sustentados em torno da culpa, da rejeição, da incapacidade, da decepção, classificando atos e sensações e atrelando-os à prematuridade. Observamos que alguns profissionais assumiam uma postura coercitiva diante de algumas mães, sem se darem conta do cotidiano na casa delas e da singularidade da vivência da prematuridade para cada uma. No entanto, embora essa questão tenha emergido nos dados coletados durante todo o estudo, ficou claro que a importância do programa é inegável.

\section{CONSIDERAÇÕES FINAIS}

Observamos em nossa pesquisa sobre o Programa Mãe Canguru que as condições da maternagem no interior da prematuridade é algo muito complexo, pois é atravessado pela vivência do trauma da culpa e do medo de perder o bebê, pela visão da fragilidade da criança, mas apesar dessas feridas o programa mãecanguru possibilita, sim, a conexão entre mãe e bebê. No momento em que a mãe pode sentir o bebê junto a seu seio, seu calor e sua presença, ela pode investir nessa criança e apostar no seu crescimento, ou seja, aceitar que, apesar de todos os obstáculos da prematuridade, o bebê possui potencial próprio para o amadurecimento. Com certeza, não é fácil para mãe aderir ao Programa Canguru, pois o fantasma da morte atravessa esse cotidiano; mas a mãe que consegue enfrentar de forma ativa nesse processo oferece ao filho prematuro um ambiente suficientemente bom para favorecer o seu crescimento.

Nesse sentido, o programa Mãe-Canguru não é desprovido de contradições e dificuldades, todavia oferece, de fato, uma possibilidade de conexão entre a mãe e o bebê. È uma importante estratégia que busca promover um melhor desenvolvimento do bebê nascido prematuramente e possui como tarefa convocar a alteridade, o lidar com a diferença, com a singularidade da subjetividade de cada mãe, de cada psiquismo envolvido no percurso de enfrentar a prematuridade. Acreditamos que o referido programa torna-se inventivo, cultiva novos modos de existência e convoca múltiplas direções quando aposta nessa singularidade, na maneira única de cada mãe ser mãe, na disponibilidade de cada pai em participar, na forma de cada família se vincular ao bebê. Ter uma atitude de respeito com esses processos pode favorecer a construção de vínculos bem como a produção e manutenção de saúde. 


\section{REFERÊNCIAS}

Andreani, G., Custodio, Z. A. O. \& Crepaldi, M. A. (2006). Tecendo as redes de apoio na prematuridade. Aletheia, 24, 115-126.

Bardin, L. (1994). Análise de conteúdo. Lisboa: Edições 70.

Boudon, R. \& Bourricaud, F. (1993). Estratificação social. Em Dicionário Crítico de Sociologia (p. 214). São Paulo: Ática.

Chizzotti, A. (1998). Pesquisa em ciências humanas e sociais. (2 $2^{\mathrm{a}} \mathrm{ed}$.) São Paulo: Cortez.

Colameo, A. J., Rea, M. F. (2006). O Método Mãe Canguru em hospitais públicos do Estado de São Paulo, Brasil: uma análise do processo de implantação. Cadernos de Saúde Pública, 22(3) Recuperado em 08 de junho de 2007 em http://www.scielo.br/scielo.php?script=sci_arttext\&pid=S0102$311 X 2006000300015 \& \operatorname{lng}=\mathrm{pt} \& \mathrm{nrm}=$ iso

Dias, E. O. (2003). A teoria do amadurecimento de D. W. Winnicott. Rio de Janeiro: Imago.

González Rey, F. L. (2002). Pesquisa qualitativa em Psicologia. São Paulo: Pioneira Thomson Learning.

Freud, S. (1989). Além do princípio do prazer. (J. Salomão, Trad.). Em Freud, S. (1989). Edição Standard Brasileira das Obras Psicológicas Completas (Vol. XVIII, pp.13-88). Rio de Janeiro: Imago. (Original publicado em 1920).

Freud, S. (1989). A dissolução do complexo de Édipo. (J. Salomão, Trad.). Em Freud, S. (1989). Edição Standard Brasileira das Obras Psicológicas Completas (Vol. XIX, pp. 215-226). Rio de Janeiro: Imago. (Original publicado em 1924)
Foucault, M. (1996). Microfísica do poder. Rio de Janeiro: Edições Graal.

Ministério da Saúde. (2004). HumanizaSUS. Documento base para gestores e trabalhadores do Sistema Único de Saúde. Recuperado em 09 de junho de 2007 em http://portal.saude.gov.br/portal/arquivos/pdf/doc_base.pdf

Ministério da Saúde. (2002). Manual do Método Mãe Canguru. Brasília: Ministério da Saúde.

Moura, S. M. S. R. \& Araujo, M. F. (2005). Produção de sentidos sobre a maternidade: uma experiência no Programa Mãe Canguru. Psicologia em Estudo, 10(1). Recuperado em 02 de março de 2007 em http://www.scielo.br/scielo.php?script=sci_arttext\&pid=S1413$73722005000100006 \& \operatorname{lng}=$ pt\&nrm=iso

Segre, C. A. M. (2002). Perinatologia: fundamentos e prática. São Paulo: Sarrier.

World Health Organization - WHO. (1961). Public health aspects of low birth weight. Geneva, (Technical Report Series, 217).

Recebido em 21/02/2007 Aceito em 01/10/2008

Endereço para correspondência :

Roberta Carvalho Romagnoli. Rua Terra Nova 101/401 Bairro Sion, CEP 30315-470, Belo Horizonte-MG, Brasil. E-mail: robertaroma@uol.com.br. 